\title{
Penggunaan Metode Multi Threads untuk Pengelolaan Proses Download di Internet
}

\author{
Zen Munawar, S.T., S.Kom., M.Kom \\ Program Studi Manajemen Informatika \\ Politeknik LP3I Bandung \\ Jl.Pahlawan No. 59 Bandung, Indonesia \\ E-mail:munawarzen@gmail.com
}

\begin{abstract}
Abstrak : Penelitian ini bertujuan merancang aplikasi download manager yang dapat mengatur beberapa proses download sekaligus dengan metode multi-thread pada sebuah aplikasi download yang efisien dan membandingkan aplikasi yang dibuat dengan aplikasi yang sudah ada. Hasil penelitian ini diharapkan dapat memberikan kegunaan bagi pengguna internet dalam melakukan proses download file dengan sebuah aplikasi yang dapat menangani beberapa proses download serta memberikan pilihan thread (eksekusi download terhadap file) dengan metode multi-thread. Hasil pengujian pada penelitian ini, aplikasi yang dibuat setara dengan aplikasi berlisensi yang sudah ada.
\end{abstract}

Kata kunci : download, download manager, thread, multi-thread

\section{Pendahuluan}

Informasi dapat diperoleh dari internet, untuk memperoleh informasi tersebut tersedia fasilitas yang disebut download.

Download merupakan proses transfer data dari server ke client. Agar data dapat sampai ke client, maka harus melalui lalu lintas jaringan. karena lalu lintas jaringan internet semakin padat, terkadang user yang melakukan download sering mengalami kegagalan. Hasilnya data tidak sampai atau data sampai ke pengguna namun dalam keadaan rusak atau koneksinya terputus ditengah proses sehingga pengguna harus mengulangi proses download dari awal.

Masalah di atas dapat diperbaiki dengan memperbaiki kinerja download, antara lain dengan membuat download manager yang dapat mengatur proses download tersebut. Jika saat proses download koneksinya tiba-tiba terputus maka pengguna dapat melanjutkan proses tersebut tanpa harus mengulangnya dari awal. Konsep multi-thread ini diterapkan pada perangkat lunak.

Tujuan dari peneitian ini adalah merancang aplikasi download manager yang dapat mengatur beberapa proses download sekaligus, menerapkan metoda multithread pada sebuah aplikasi download yang efisien, membandingkan aplikasi yang dibuat dengan aplikasi berlisensi yang sudah ada.

Setelah implementasi dilakukan pengujian untuk mengetahui kinerja aplikasi dengan membandingkan dengan aplikasi yang sudah ada. 
Hasil penelitian ini diharapkan dapat memberikan aplikasi alternatif bagi pengguna dalam proses download file dengan sebuah aplikasi yang dapat menangani beberapa proses download serta memberikan pilihan thread dengan metode multi-thread.

\section{Metode Penelitian}

Studi pustaka, yaitu dengan membaca dan mempelajari literatur berupa teoriteori seperti : jurnal, buku, dan artikel-artikel yang. berhubungan dengan penelitian yang dilakukan.

Pengumpulan Data, Tahap mengumpulkan fakta dan informasi untuk mendapatkan informasi.

Desain dan Implementasi, dilakukan dengan cara melakukan perancangan dan implementasi sistem untuk membuat gambaran yang jelas dari masalah yang dihadapi dengan pembuatan program aplikasi.

Pengujian Fungsional, metode yang digunakan adalah black box testing untuk membatu kesalahan pada perangkat lunak dan sistem dapat berjalan sesuai dengan kebutuhan, serta membandingkan hasil dengan aplikasi yang sudah ada.

\section{Landasan Teori}

Download merupakan sebuah proses dalam pentransferan dari satu komputer ke komputer lain dalam suatu jaringan, tipikalnya dari komputer host, atau sebuah network server ke sebuah Personal Computer (PC) atau sebuah Workstation.

Thread merupakan abstraksi yang mendefinisikan sebuah alur eksekusi. Dari definisi tersebut maka multi-thread dapat disebut sebagai abstraksi yang memiliki alur eksekusi lebih dari satu.

Multi-thread merupakan perluasan dari paradigma dari multitasking. Multitasking adalah kemampuan komputer untuk melakukan banyak tugas secara konkuren. Pada multitasking, konkurensi melibatkan banyak proses. Perbedaannya dengan multi-thread adalah multi-thread lebih menggunakan banyak benang (thread) kendali dalam satu proses. (Bambang Hariyanto, 2003)

Java adalah bahasa pemrograman kelanjutan dari bahasa pemrograman $\mathrm{C}$ dan $\mathrm{C}++$. Terdapat beberapa kemiripan antara Java dengan $\mathrm{C}$ atau $\mathrm{C}++$ namun Java memilki ciri khas tersedia yang membedakannya dengan kedua bahasa tersebut. antara lain: Platform independence, Berorientasi Objek, Java API, Internet

Unified Modeling Language (UML) adalah satu set notasi dan konvensi yang digunakan untuk menggambarkan dan memodelkan sebuah aplikasi. Tetapi, UML. tidak menspesifikasikan sebuah metodologi atau langkah apa yang perlu diambil dalam pengembangan perangkat lunak. hal tersebut merupakan tugas dari pendekatan unified (Unified Approach-UA) (Sholiq : 2006). 
UML memiliki 3 aspek utama (Sinan Si Alhir : 2003) yaitu Bahasa, Model dan Unified.

Untuk sistem yang rumit, pendekatan terbaik adalah dengan memodelkan, sehingga tidak ada satu pun titik pandang yang akan kekurangan. Setiap model mungkin diekspresikan pada tingkatan ketelitian yang berbeda (Sholiq : 2006). Model yang terbaik adalah model yang berhuhungan dengan kenyataan. Pada Penelitian ini digunakan grafik diagram : Use-case Diagram, Activity Diagram, Package Diagram.

Booth menerangkan bahwa menggambarkan sebuah kegiatan secara sistemasi dalam sebuah media yang statis seperti di atas selembar kertas sangatlah sulit, tetapi masalah tersebut dihadapi oleh kebanyakan disiplin ilmu. Pada pengembangan berorientasi objek, anda dapat mengekspresikan

"Pengujian perangkat lunak adalah elemen kritis dari jaminan kualitas perangkat lunak dan merepresentasikan kajian pokok dari analisis , desain dan pengkodean" . (Roger S. Pressman, 1997 : 525).

Semua produk yang direkayasa dapat diuji dengan satu atau dua cara yaitu black box testing dan white box testing (Roger S. Pressman, 1997 : 532):

\section{Analisis}

Analisis sistem dapat didefinisikan sebagai penguraian dari suatu sistem yang utuh kedalam bagian-bagian komponennya dengan maksud untuk mengidentifikasi dan mengevaluasi permasalahan-permasalahan, kesempatan-kesempatan, hambatan-hambatan yang terjadi dan kebutuhankehutuhan yang diharapkan sehingga dapat diusulkan perbaikanperbaikannya. (Jogiyanto HM, 2002)

Sebuah download manager mengidentitikasi alamat file bukan alamat website dari file tersebut. Oleh karena itu dibutuhkan sebuah inputan alamat lengkap yang akurat.

Analisis Output Aplikasi, Output dari sebuah aplikasi download manager adalah laporan dari proses download yang meliputi kecepatan transfer file, waktu download dan sukses tidaknya sebuah proses download.

Analisis terhadap sistem yang telah berjalan penulis menggunakan perangkat lunak pembanding. Download manager adalah perangkat lunak yang dapat menangani beberapa proses download sekaligus. Disini penulis menggunakan aplikasi download komersial Download Accelerator Plus (DAP) sebagai perangkat lunak pembanding. Namun disini penulis menggunakan versi Trial dari perangkat lunak tersebut. 


\section{Flow Chart :}

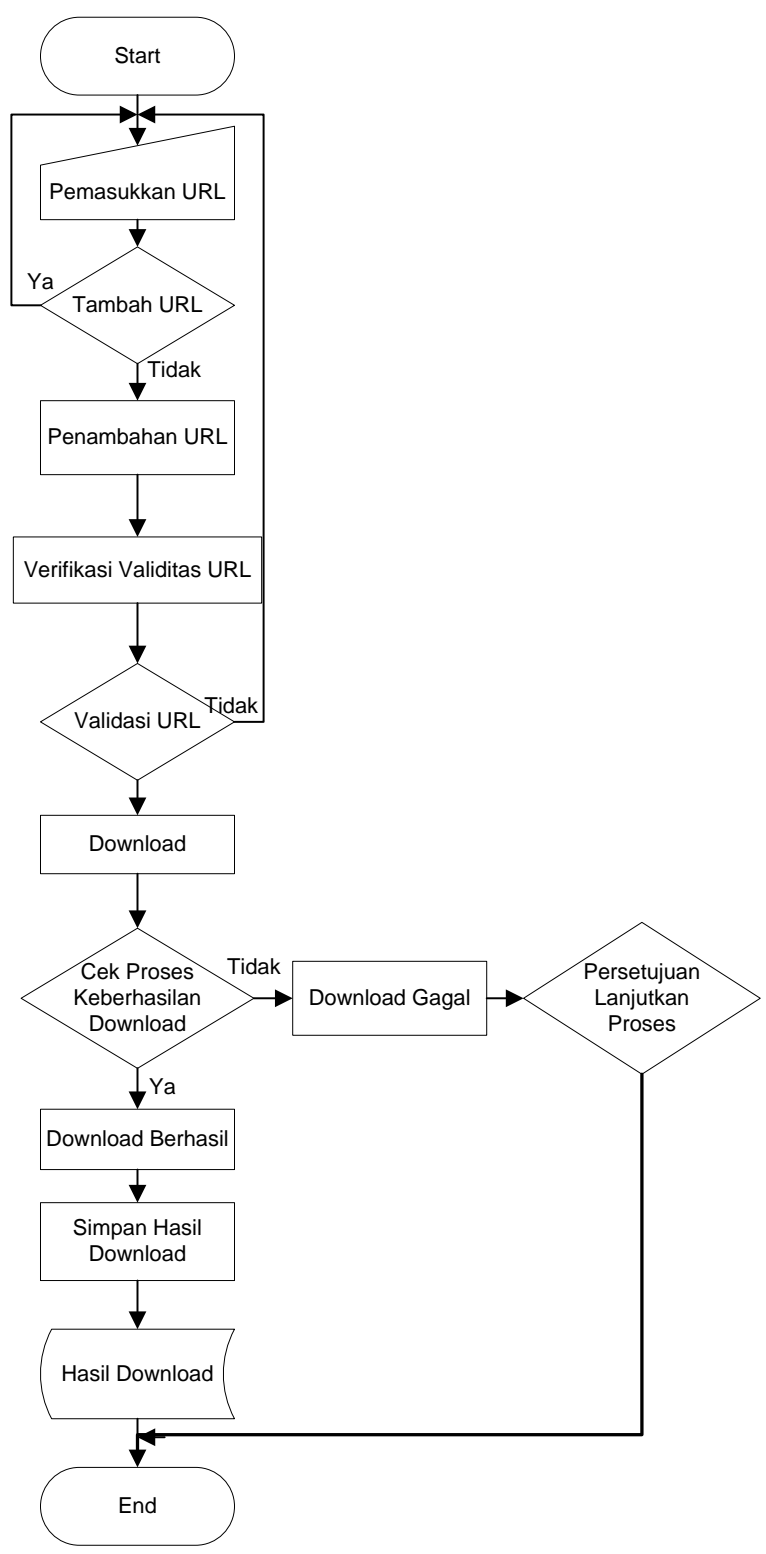

Gambar Flow Chart dari Aplikasi DAP

Analisis Perangkat Lunak, Sebuah aplikasi download manager harus memiliki kemampuan yaitu memiliki field, fasilitas, fungsi, informasi, fungsi konfigurasi. Untuk membangun perangkat lunak ini dibutuhkan beberapa perangkat lunak pendukung, yaitu : Sistem Operasi MS Windows XP SP2, Browser MS IE atau Mozilla Firefox, Java Netbeans 6.9, Apache Server.

Analisis Kebutuhan Perangkat Keras, Untuk membuat aplikasi download manager ini dibutuhkan sebuah perangkat lunak dengan spesifikasi berikut CPU Pentium IV 2.4 GHz, Ram 1 Gb, Hard Disk ATA 80 MB 5400 rpm, Modem Terintegrasi, Monitor Standar, Keyboard dan Mouse. 
Analisis Brainware, Analisis brainware dilakukan untuk mengidentifikasi kelayakan atau kemampuan seseorang yang akan menggunakan aplikasi yang dibuat.

\section{Perancangan dan Pengujian}

Perancangan Sistem, Pemodelan aplikasi menggunakan UML (Unified Modeling Language). Dalam perancangannya digunakan pemodelan dengan diagram sebagai berikut Use Case Diagram, Activity Diagram, Class Diagram

Use Case Diagram, Use case diagram menggambarkan fungsionalitas sistem atau persyaratan-persyaratan yang harus dipenuhi sistem dari pandangan pemakai.

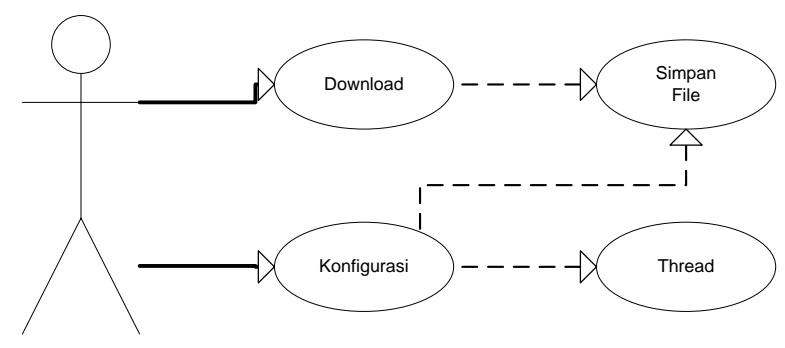

Gambar Use Case Diagram aplikasi download manager

Activity Diagram (Diagram Aktivitas), digunakan untuk memodelkan aliran kerja (workflow) dalam perangkat lunak.
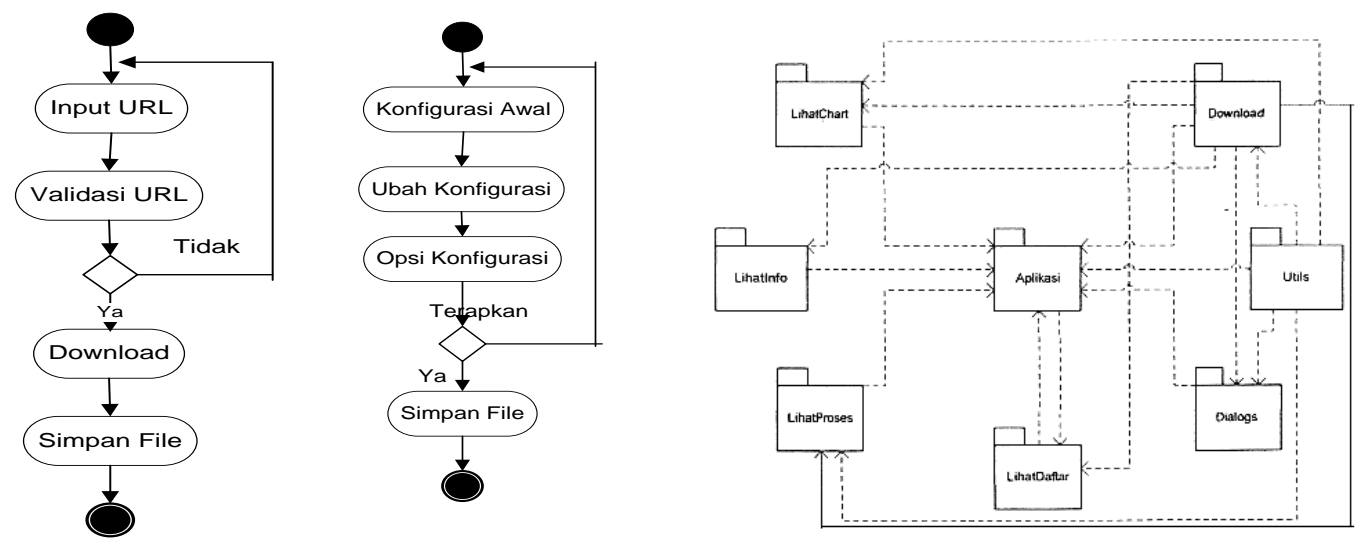

Gambar Diagram aktivitas proses download, proses Konfigurasi, kelas

Diagram Aktivitas Proses konfigurasi, Berikut ini dijabarkan aliran kerja pada proses konfigurasi download dari aplikasi.

Rancangan Class Diagram (Dagram Kelas), digunakan untuk menampilkan kelas-kelas atau paket-paket di dalam suatu sistem dan relasi antar kelas-kelas tersebut. Diagram kelas atau paket memberikan gambaran 
secara static yang digunakan untuk membangun sumber kode pemhangunan aplikasi yang dirancang.

Berikut adalah gambaran rancangan paket-paket dan relasinya yang digunakan dalam aplikasi download manager :

Gambar tersebut menjelaskan bahwa tiap-tiap kelas dari aplikasi memiliki dependency (ketergantungan) satu sama lainnya. Kelas-kelas ini mempunyai fungsi masing-masing dimana hasil dari fungsi dari kelas tersebut selanjutkan akan digunakan oleh kelas lain untuk memproses fungsinya.

Perancangan Antar Muka (Graphical User Interface/GUI), dibutuhkan agar pengguna aplikasi dapat mengoperasikan aplikasi dengan nyaman dan mudah. Hal ini menjadi salah satu aspek penting dalam keberhasilan aplikasi tersebut. Perancangan berikut dilakukan untuk menggambarkan desain antar muka aplikasi yang akan dibangun.

Perancangan Form Utama Aplikasi, memuat tombol-tombol untuk download, label informasi proses download dan tab untuk melakukan konfigurasi.
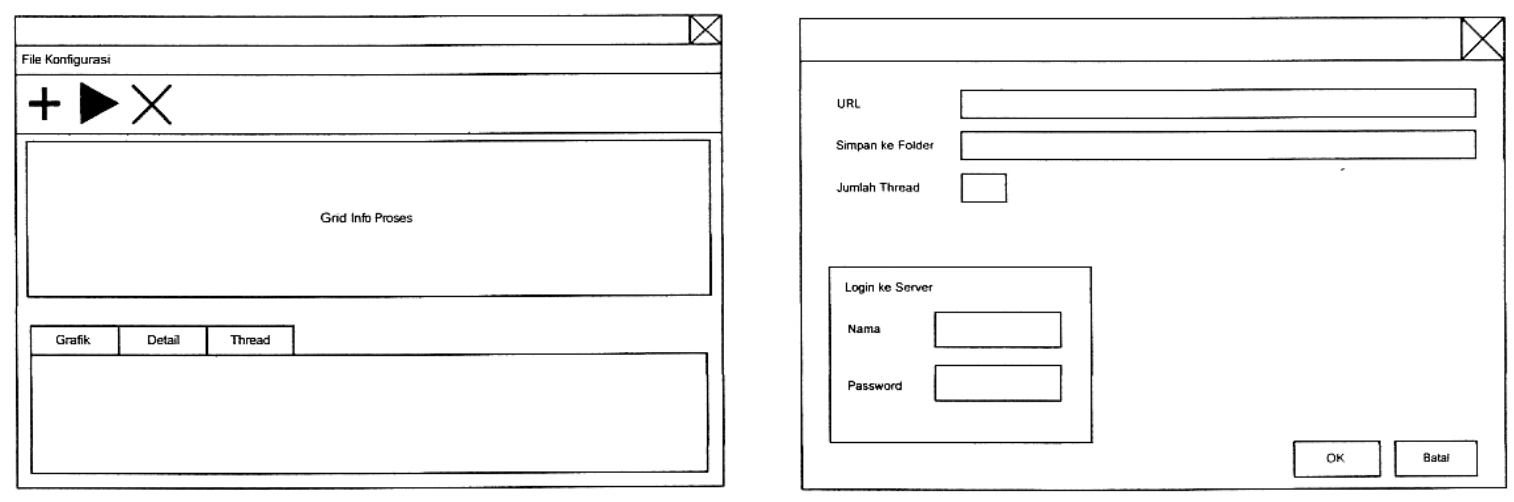

Gambar 5.3 Rancangan form Utama Aplikasi dan Rancangan form Tambah download

Perancangan Form Tambah Download, dibangun untuk melakukan proses download, terdapat field untuk penginputan $U R L$, menentukan di folder mana file akan disimpan, jumlah thread serta fasilitas login ke website server tujuan.

Perancangan Form Menu Konfigurasi, berisi setting-setting untuk proses download, disini akan tersedia berbagai konfigurasi dari aplikasi yang dibuat.

Perancangan Form Konfigurasi Global, berisi setting folder, jumlah thread dan dimana database aplikasi akan dibuat. 

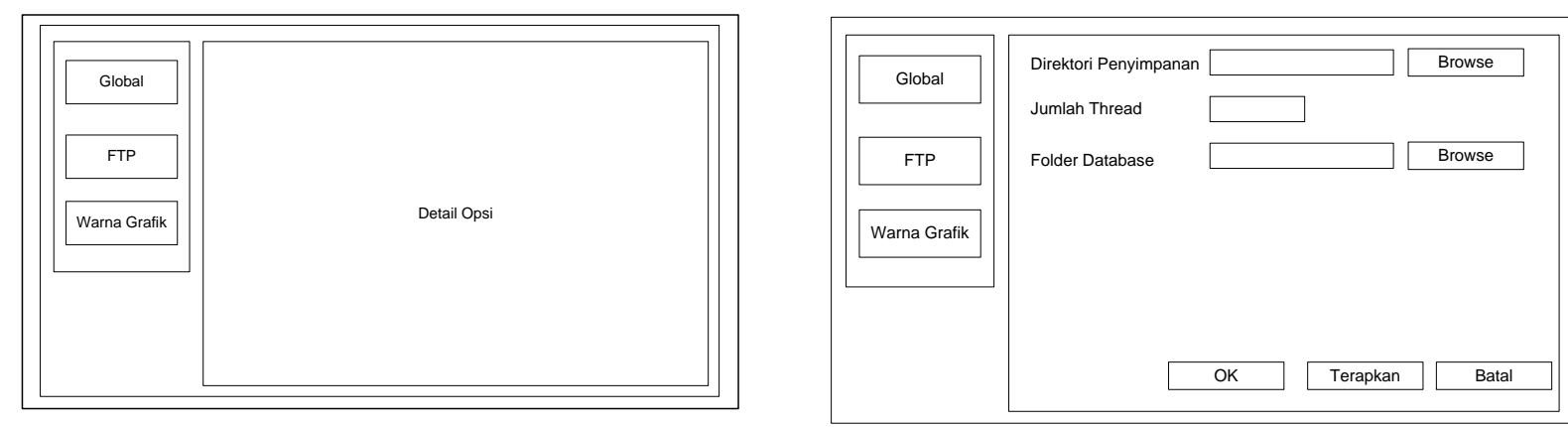

Gambar 5.6 Rancangan Menu form Konfigurasi dan form Konfigurasi Global

Perancangan Form Konfigurasi FTP dan Form Konfigurasi Warna Grafik
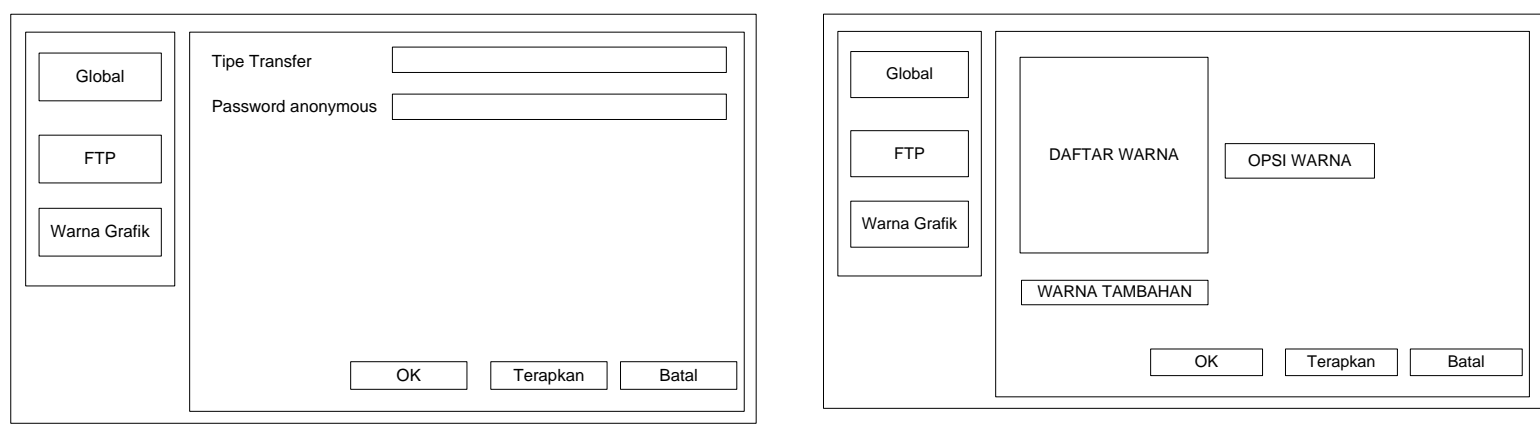

Gambar 5.7 Rancangan form konfigurasi FTP dan Form Konfigurasi Warna Grafik

Pengujian, merupakan suatu elemen kritis dari jaminan sistem yang telah dibuat dan merepresentasikan kajian pokok dari spesifikasi, desain dan pengkodean.

Pengujian Tampilan, Pengujian tampilan dilakukan untuk melihat apakah aplikasi yang telah dibuat dapat diakses dengan baik dalam sistem komputer.

Tabel 5.1 Pengujian Tampilan

\begin{tabular}{|c|l|c|c|}
\hline \multirow{2}{*}{ No. } & \multicolumn{1}{|c|}{ Modul } & \multicolumn{2}{|c|}{ Berhasil } \\
\cline { 3 - 4 } & & Ya & Tidak \\
\hline 1 & Form Utama & X & \\
\hline 2 & Form Tambah Download & X & \\
\hline 3 & Form Menu Konfigurasi & X & \\
\hline 4 & Form Menu Konfigurasi Global & X & \\
\hline 5 & Form Menu Konfigurasi FTP & X & \\
\hline 6 & Form Menu Konfigurasi Warna Grafik & \multicolumn{2}{|c|}{} \\
\hline
\end{tabular}




\section{Tampilan Form Utama dan Form Tambah Download}
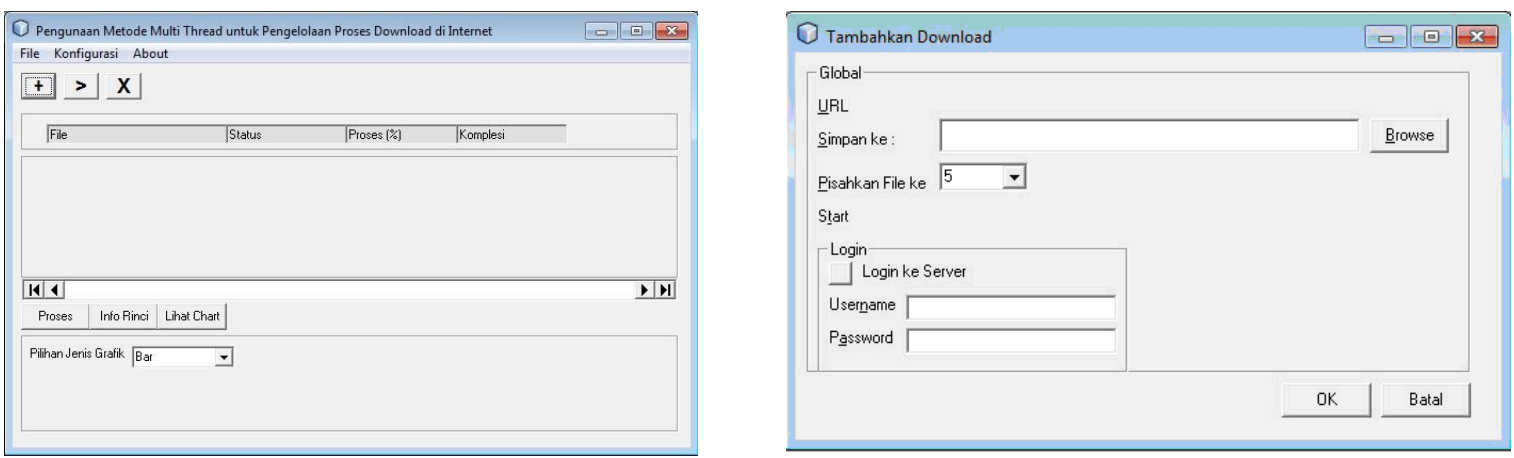

Gambar 5.8 Tampilan Form Utama dan Form Tambah Download

\section{Tampilan Form Menu Konfigurasi}
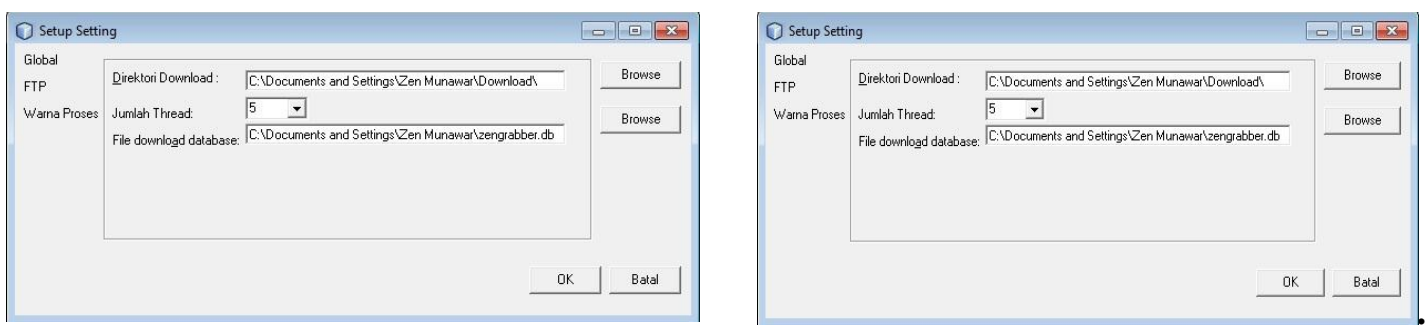

Gambar 5.9 Tampilan Form Menu Konfigurasi dan Form Menu Konfigurasi Global

\section{Tampilan Form Konfigurasi FTP dan Form Konfigurasi Warna Grafik}
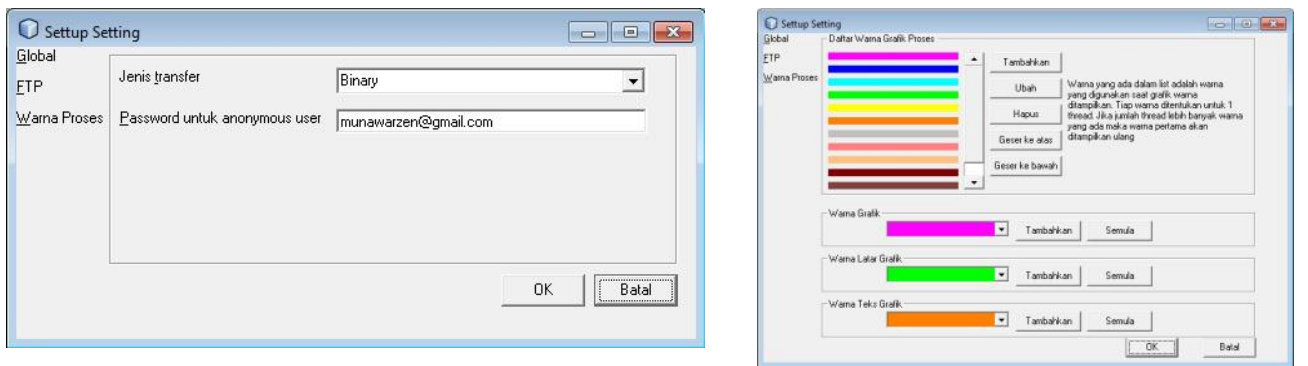

Gambar 5.10 Tampilan Form Konfigurasi Form FTP dan Konfigurasi Warna Grafik

Pengujian Fungsional, Pengujian dilakukan dengan menguji fungsi dari aplikasi seperti pengujian pen-download-an beberapa file, pengujian download dengan jumlah thread yang berbeda dan pengujian penyimpanan file pada folder.

Pengujian Pengeksekusian Beberapa download. pada pengujian ini aplikasi diuji dengan mengeksekusi beberapa proses download sekaligus. Berikut ini tabel hasil pengujiannya : 
Tabel 5.2 Pengujian Eksekusi Beberapa Download

\begin{tabular}{|c|l|l|l|l|l|}
\hline No & \multicolumn{1}{|c|}{ Nama File } & Ukuran & \multirow{2}{*}{ Tipe File } & \multicolumn{2}{c|}{ Berhasil } \\
\cline { 5 - 6 } & & & & Ya & Tidak \\
\hline 1 & Backup4all-User-Manual.pdf & $1.88 \mathrm{Mb}$ & File PDF & $\mathrm{X}$ & \\
\hline 2 & Granule-1.3.0-.3-win32.rar & $19 \mathrm{Mb}$ & Arsip (Rar) & $\mathrm{X}$ & \\
\hline 3 & Speedygnfs11-ch.zip & $126 \mathrm{~Kb}$ & Arsip (Zip) & $\mathrm{X}$ & \\
\hline
\end{tabular}

Dari hasil pengujian diatas dapat dilihat bahwa aplikasi dapat menangani beberapa proses download sekaligus.

Pengujian penyimpanan file pada folder, pengujian ini akan diuji apakah aplikasi dapat menyimpan file path folder yang ditentukan oleh user. File beserta folder tujuannya sebagai berikut : Speedygnfs-ch-zip disimpan di folder "C:Idownload", Backup4all-User-Manual.pdf, disimpan di folder "C:Zen Munawar Files\Download", Granule-1-3.3.0-3-win32.rar, disimpan di folder "C:IDocument and Settings\Zen Munawar"

Tabel 5.3 Hasil Pengujian Penyimpanan File

\begin{tabular}{|c|l|l|c|c|}
\hline No & \multicolumn{1}{|c|}{ Nama File } & \multicolumn{1}{c|}{ Hasil Download } & \multicolumn{2}{|c|}{ Sesuai } \\
\cline { 4 - 5 } & & & Ya & Tidak \\
\hline 1 & Speedygnfs11-ch.zip & C:Idownload & X & \\
\hline 2 & Backup4all-User-Manual.pdf & C: Zen Munawar FilesLDownload & x & \\
\hline 3 & Granule-1.3.0.3-win32.rar & C:IDocument and SettingsIZn Munawar & x & \\
\hline
\end{tabular}

Dari pengujian diatas dapat dilihat aplikasi dapat menyimpan file hasil download di folder yang telah ditentukan oleh $u$ ser.

Pengujian Akselerasi Waktu, dilakukan untuk mengetahui waktu pendownload-an dengan men-download 2 file yang berbeda tipe ukuran.

Dikarenakan traffic Internet yang selalu herubah-ubah maka pengujian dilakukan sebanyak 5 kali kemudian diambil waktu rata-ratanya. Thread maksimum pengujian adalah 5. Berikut ini hasil penguiiannya: File 1 Nama File : speedygnfs11-ch.zip, Ukuran $126 \mathrm{~Kb}$,

Tabel 5.4 Akselerasi waktu download tiap thread file 1

\begin{tabular}{|c|c|c|c|c|c|c|}
\hline \multirow{2}{*}{$\begin{array}{l}\text { Jumlah } \\
\text { Thread }\end{array}$} & \multicolumn{5}{|c|}{ Waktu (detik) di Percobaan Ke- } & Rata-rata \\
\cline { 2 - 6 } & $\mathbf{1}$ & $\mathbf{2}$ & $\mathbf{3}$ & $\mathbf{4}$ & $\mathbf{5}$ & Waktu \\
\hline 1 & 36 & 30 & 32 & 38 & 30 & 33,2 \\
\hline 2 & 25 & 30 & 30 & 32 & 31 & 29,6 \\
\hline 3 & 27 & 25 & 27 & 31 & 33 & 28,6 \\
\hline 4 & 26 & 27 & 26 & 29 & 32 & 28 \\
\hline 5 & 24 & 26 & 27 & 30 & 29 & 27,2 \\
\hline
\end{tabular}

File 2 , Nama File : Backup4all-User-Manual.pdf, Ukuran 1,88 Mb 
Tabel 5.5 Akselerasi waktu download tiap thread file 2

\begin{tabular}{|c|c|c|c|c|c|c|}
\hline \multirow{2}{*}{$\begin{array}{c}\text { Jumlah } \\
\text { Thread }\end{array}$} & $\mathbf{1}$ & $\mathbf{2}$ & $\mathbf{3}$ & $\mathbf{4}$ & $\mathbf{5}$ & $\begin{array}{c}\text { Rata-rata } \\
\text { Waktu }\end{array}$ \\
\hline & 386 & 370 & 395 & 383 & 387 & 384,2 \\
\hline 2 & 387 & 383 & 390 & 377 & 375 & 382,4 \\
\hline 3 & 389 & 388 & 371 & 380 & 370 & 379,6 \\
\hline 4 & 383 & 378 & 381 & 378 & 377 & 379,4 \\
\hline 5 & 385 & 379 & 380 & 381 & 369 & 378,8 \\
\hline
\end{tabular}

Dari pengujian download 2 file diatas dapat dilihat bahwa tiap peningkatan thread akan memberikan tambahan akselerasi waktu. meskipun tidak telalu signifikan.

Pengujian dengan perbanding, Sebagai pembanding penulis menggunakan aplikasi komersil Download Accelerator Plus Trial .Pengujian dilakukan membandingkan fasilitas dan akselertsi waktu kedua aplikasi.

Tabel 5.6 Uji Banding Fitur

\begin{tabular}{|c|l|c|c|}
\hline No & \multicolumn{1}{|c|}{ Kriteria pembanding } & Aplikasi yang dibuat & DAP Versi Trial \\
\hline 1 & Proses download $>=1$ & Ya & Ya \\
\hline 2 & $\begin{array}{l}\text { Meneruskan proses download } \\
\text { setelah mengalami kegagalan }\end{array}$ & Ya & Ya \\
\hline 3 & Opsi Multi-thread & Ya & Tidak \\
\hline 4 & Koneksi ke FTP & Ya & Ya \\
\hline 5 & Fungsi Upload & Tidak & Ya \\
\hline 6 & Opsi folder penyimpanan & Ya & Ya \\
\hline 7 & Laporan proses & Ya & Ya \\
\hline 8 & Laporan tiap thread & Ya & Tidak \\
\hline
\end{tabular}

Uji Akselerasi Waktu Apiikasi Pembanding, DAP Plus Trial diuji akselerasi waktunya dahulu sebelum dibandingkan dengan aplikasi yang dibuat.

File 1 Nama File : speedygnfsl I-ch.zip, Ukuran : $126 \mathrm{~Kb}$

Tabel 5.7 Waktu download file I

\begin{tabular}{|c|c|c|c|c|c|c|}
\hline \multirow{2}{*}{$\begin{array}{l}\text { Jumlah } \\
\text { Thread }\end{array}$} & \multicolumn{5}{|c|}{ Waktu (detik) di percobaan ke } & \multirow{2}{*}{ Rata-rata waktu } \\
\hline & 1 & 2 & 3 & 4 & 5 & \\
\hline & 34 & 24 & 26 & 27 & 25 & 27,2 \\
\hline
\end{tabular}

File 2 Nama File Backup4all-User-Manual.pdf, Ukuran $\quad: 1,88 \mathrm{Mb}$ 
Tabel 5.8 Waktu download file 2

\begin{tabular}{|c|c|c|c|c|c|c|}
\hline \multirow{2}{*}{$\begin{array}{l}\text { Jumlah } \\
\text { Thread }\end{array}$} & \multicolumn{5}{|c|}{ Waktu (detik) di percobaan ke } & \multirow{2}{*}{ Rata-rata waktu } \\
\hline & 1 & 2 & 3 & 4 & 5 & \\
\hline & 373 & 379 & 377 & 387 & 379 & 27,2 \\
\hline
\end{tabular}

\section{Perbandingan Akselerasi Waktu}

Berikut ini adalah perbandingan akselerasi waktu antara aplikasi yang dibuat dengan aplikasi pembanding. File 1 Nama File : speedygnfs11-ch-zip, Ukuran 126 $\mathrm{Kb}$

Tabel 5.9 Perbandingan Akselerasi Waktu pada Download File 1

\begin{tabular}{|l|c|c|c|c|c|c|}
\hline \multirow{2}{*}{} & \multicolumn{4}{|c|}{ Aplikasi yang dibuat } & \multirow{2}{*}{$\begin{array}{c}\text { DAP } \\
\text { Trial }\end{array}$} \\
\cline { 2 - 6 } & 1 & 2 & 3 & 4 & 5 & \\
\hline Rata-rata Waktu & 33,2 & 29,6 & 28,6 & 28 & 27,2 & 27,2 \\
\hline
\end{tabular}

File 2 Nama File Backup4all-User-Manual.pdf, Ukuran 1,88 Mb

Tabel 5.10 Perbandingan Akselerasi Waktu pada Download File 2

\begin{tabular}{|c|c|c|c|c|c|c|}
\hline \multirow{4}{*}{} & \multicolumn{5}{|c|}{ Aplikasi yang dibuat } & DAP \\
& \multicolumn{5}{|c|}{ Thread } \\
\cline { 2 - 6 } & 1 & 2 & 3 & 4 & 5 & Trial \\
\hline Rata-rata Waktu & 384,2 & 382,4 & 379,6 & 379,4 & 378,8 & 379 \\
\hline
\end{tabular}

Dilihat dari kedua hasil pengujian diatas, aplikasi yang dibuat bisa dikatakan setara dengan aplikasi pembanding Download Accelerator Pro.

\section{Implementasi Sistem}

Implementasi Sistem merupakan langkah lanjut dari tahap perancangan dan pengujian. Implementasi sistem mencakup segala kebutuhan aplikasi yang dibuat agar aplikasi dapat berjalan dengan lancar. Berikut ini adalah hasil tampilan aplikasi download manager yang telah dibuat. 


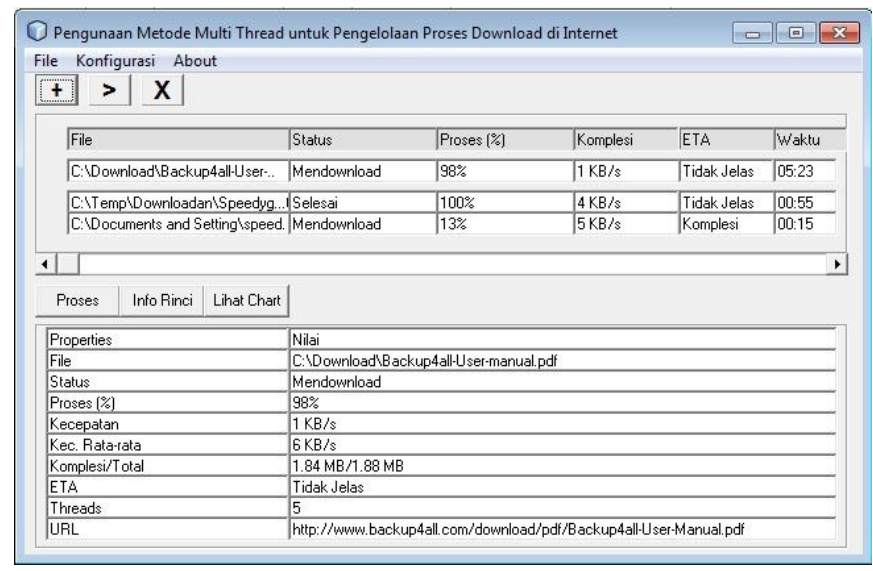

Gambar 6.1 Hasil Implementasi

\section{Kesimpulan}

Terdapat beberapa hal yang dapat disimpulkan sebagai berikut :

1. Aplikasi yang dibuat dapat menangani proses download lebih dari satu. Proses-proses download yang sedang berjalan dapat dilihat dalam label info pada aplikasi, lengkap dengan komplesi proses, estimasi waktu, waktu transfer, kecepatan transfer dan terdapat diagram (chart) agar mempermudah user memperoleh informasi mengenai proses downloud yang sedang berlangsung.

2. Metoda multi-thread dapat diterapkan pada aplikas, pentransferan file dapat dieksekusi per bagian.

3. File hasil download bisa disimpan pada folder khusus, baik itu folder hasil penyetelan user maupun folder default dari aplikasi.

\section{Daftar Pustaka}

[1] Chonoles, Michael Jesse, A Schardt James, 2003, Unified Modelling Language 2, Wiley Publishing, Inc., New York

[2] Eddings, Joshua, 2003, How Internet Works, California

[3] Hariyanto, Bambang, 2003, Esensi-esensi Bahasa Pemrograman Java, Informatika, Bandung

[4] Jogiyanto HM,2001., Analisis \& Desain Sistem Informasi : Pendekatan Terstruktur Teori dan Praktek Aplikasi Bisnis, Andi Offset, Yogyakarta.

[5] Lowe, Doug, 2005, Java All-In-One Desk Reference, Wiley Publishinh, Inc, New Jersey

[6] Oaks, Scott., Wong, Henry, 2001, Java Threads 2nd, O'Really, California

[7] Sholiq, 2006, Pemodelan Sistem Informasi Berorientasi Objek dengan UML, Graha Ilmu, Yogyakarta.

[8] SI Alhir, Sinan, 2003, Learning UML, O’Really, California

[9] Westnet Learning Techonolgies and Digital Creator, 1998, Networking Fundamental, WestNet, Washington D.C. 